RESENHA

\title{
A trama autoritária: direitas e violência no Uruguai
}

The authoritarian plot: rights and violence in Uruguay

La trama autoritaria: derechas y violencia en Uruguay

RESENHA DE:

BROQUETAS, Magdalena. La trama autoritaria: derechas y violencia en Uruguay (1958-1966). Montevideo: Ediciones de La Banda Oriental, 2014. 280 p.

\section{Somos os derrotados provisórios de um destino injusto}

Com essa frase endereçada a Lucien Febvre, Marc Bloch fez uma triste, porém correta reflexão da queda da França diante da Alemanha nazista. Uma afirmação que poderia ser aplicada às Ditaduras de Segurança Nacional da América Latina, ou, para ser mais correto, à derrota das esquerdas diante da ascensão das direitas radicais na segunda metade do século XX. É um processo que atingirá em maior ou menor grau praticamente todos os países, principalmente no Cone Sul do continente.

Logicamente, devemos compreender os contextos internos e externos que redundaram em tais processos. Do ponto de vista externo, precisamos levar em consideração a Guerra Fria que polarizava em blocos opostos Estados Unidos e União Soviética, deixando pouco espaço para qualquer ação independente desses polos. A Revolução Cubana acirra ainda mais as disputas dentro do continente, fazendo com que os Estados Unidos "retomem" a "velha teoria" do big stick do século XIX e comecem a agir de forma a valer seus interesses pela força das armas, financiando e organizando golpes de estado, 
como sendo fundamentais na construção de toda uma rede de terrorismo de Estado. Isso servia aos interesses de Washington para retomar o controle e fazer a manutenção daquilo o que consideravam o "seu quintal".

Internamente, o fenômeno do populismo latino-americano, iniciado nas décadas de 1930 e 1940, cristalizava-se nas décadas de 1950 e 1960, gerando a ascensão social, política e econômica de operários e camponeses nos países do continente. Embora tal fato expandisse o capitalismo local, assustava as elites tradicionais, historicamente temerosas de uma ascensão popular que pudesse romper com as barreiras do status quo de seu domínio social.

Este é um fenômeno característico que se multiplicou na segunda metade do século XX, cujos reflexos permanecem latentes nas "veias abertas da América Latina". A partir da década de 1990, a questão da direita começou a chamar a atenção dos historiadores em seus respectivos países e com temáticas distintas. Uma parcela de tais estudos centralizou-se em uma análise das esquerdas, em oposição a uma noção difusa da Doutrina de Segurança Nacional, que guiava as ditaduras dentro de uma lógica na qual o inimigo interno era tão perigoso como o inimigo externo.

De forma simplista tais processos passaram a ser explicados. Porém, grandes lacunas ficavam abertas, que precisavam - e ainda precisam - ser elucidadas. Ou seja, em nossa historiografia latino-americana existe uma grande necessidade de compreensão da ação da direita, tanto na gestação como nos golpes, no financiamento e na condução dos governos ditatoriais.

Uma das obras que busca suprir tal necessidade de elucidação sobre o pensamento e a práxis da direita é a obra La trama autoritaria: derechas y violencia en Uruguai (1958-1966) da historiadora uruguaia Magdalena Broquetas. Docente e pesquisadora da Faculdad de Humanidades y Ciências de La Educación de la Universidad de la República, dedica-se ao estudo da história recente uruguaia. ${ }^{1}$

A partir de uma extensa e heterogênea documentação em arquivos de seu país e do exterior, a autora consegue, de forma magistral, tecer um rico panorama da ação da direita uruguaia que posteriormente

\footnotetext{
${ }^{1}$ Magdalena Broquetas também faz parte da Rede Internacional de Investigação "Direita, História e Memória", grupo sediado no Brasil e que busca convergir pesquisadores de vários países que se dedicam ao estudo da Direita. Endereço do sítio eletrônico: <http: \|www. direitashistoria.net>
} 
culminaria, na década de 1970, na ditadura iniciada por Juan María Bordaberry. ${ }^{2}$

O primeiro capítulo da obra é destinado a uma maior compreensão da gestação da direita uruguaia no século XX. Inicia tentando compreender o que é a "direita" no campo político de seu país e quais são as suas faces e suas inter-relações. Aliás, logo de início a autora apresenta uma das angústias que atingem muitos dos pesquisadores que se dedicam a analisar as direitas:

Dos enunciados encuentran consenso entre los historiadores que en la actualidad se dedican al estudio de las derechas: en primer lugar el hecho de que, apesar de la presencia constante que estas han tenido en los procesos históricos de América Latina y Europa durante el siglo XX, no han concitado el mismo interes social ni generado el atractivo de otros objetos de investigación y, en segundo lugar, dentro del ambito historiográfico, la conformación de un campo de análisis específico es reciente y se encuentra en contrucción. (BROQUETAS, 2014, p. 29)

A partir disso, a autora compreende como se estabeleceram os marcos teóricos e como poderia ser feita a análise em uma perspectiva histórica das direitas. Partiu dos autores que em âmbito global tentaram refletir sobre a questão, tais como Sandra McGee-Deutsch e Ernesto Bohoslavsky, e compreenderam a necessidade de identificar os diversos atores sociais vinculados à direita, assim como suas fontes intelectuais, valores e aspectos de suas representações simbólicas. Também, refletirá a partir de Sergio Morresi - que foi influenciado por Pierre Bourdieu a pensar não na direita como um fenômeno no singular, mas conceber o termo no plural, ou seja, em direitas. Dessa forma, pode-se perceber que as direitas são mais complexas e multifacetadas.

Ainda no presente capítulo, Broquetas resolve um nó górdio do estudo das direitas: a reflexão do aspecto mais amplo, entre setores conservadores, liberais, autoritários e democráticos dentro do âmbito da direita. No caso específico, o texto foi construído de forma cronológica, explicitando como ocorreu a formação do fenômeno do surgimento das diversas "vertentes" da direita uruguaia e como se organizavam

\footnotetext{
2 A autora não aborda a ditadura civil-militar (1973-1985) em sua obra, porém, nos instrumentaliza com uma excelente base para compreender o processo que culminaria no período ditatorial. Como nos apresenta a autora: "Com el retorno de la democracia y la recuperación de las liberdades públicas, hace casi treinta años, se instaló en Uruguay um pleito por el relato de los processos de la década de 1960 el período prévio al golpe de Estado de 1973" (BROQUETAS, 2014, p. 15).
} 
na primeira metade do século XX. Logicamente, tal resgate tem por objetivo contextualizar o leitor para compreender como estava o "estado da arte" das direitas uruguaias entre os anos de 1958 e 1966 - recorte temporal da pesquisa.

O segundo capítulo será destinado para a compreensão contextual da Guerra Fria na América Latina, centralizando principalmente no Uruguai. O texto analisa o impacto dos conflitos exógenos e como repercutiam localmente, principalmente, como refletiam nas diversas vertentes que compunham a "trama autoritária" da direita uruguaia. Nesta parte, inicia com a mudança de "paradigma" na transição da década de 1950 para a década de 1960, na qual o tradicional Partido Colorado foi superado nas urnas pelo Partido Nacional - inicialmente chamado de Partido Blanco. Com isso, ascendeu uma aliança entre setores da oligarquia agrária que ansiava pela desestruturação de uma estrutura urbana e industrial, defendiam um liberalismo radical com o fim do controle de câmbio e a intervenção estatal na economia. Tal fato redundou em uma reestruturação do Executivo uruguaio, que passou a tomar medidas que se aproximavam com os postulados dos Estados Unidos e do Fundo Monetário Internacional para a América Latina.

Segundo a autora, tais fenômenos redundaram em uma crise econômica profunda, gerando cada vez mais endividamento externo. Quanto mais profundos se tornavam os problemas financeiros, maior dependência. Fatos que colocavam a elite governante uruguaia em uma situação complicada. Nas eleições de 1962, o Partido Nacional repetiu o triunfo de 1959. O novo governo levou ao aprofundamento da crise econômica, que teve grande impacto sobre a sociedade e, principalmente, sobre os trabalhadores e organizações sociais. No mesmo capítulo ainda é abordado o papel da América Latina na Guerra Fria, tendo destaque a questão da Revolução Cubana e as respectivas ações de Washington sobre os governos locais - principalmente os de esquerda e centro esquerda. Tais ações redundam nos golpes de estado no Brasil e República Dominicana. Finaliza refletindo sobre a ingerência estadunidense nos interesses internos do Uruguai e as operações ilegais da Agência Central de Inteligência dos EUA(CIA) em operações contra a esquerda uruguaia e também da própria ação política da embaixada ianque na mobilização das direitas uruguaias na década de 1960.

O terceiro capítulo tem um papel fundamental na organização da obra: mostra como se estruturou a ação da direita conservadora e o surgimento do anticomunismo, como uma reação ante uma possível organização popular diante da crise e da desestruturação social advinda 
dela. Nesse ponto percebe-se como os setores conservadores e liberais agiram diante da reação popular. $\mathrm{O}$ anticomunismo surgia como um mecanismo de defesa das elites tradicionais, mesmo que a esquerda comunista, não tivesse forças para a real tomada do poder. A adoção do discurso anticomunista da Guerra Fria, atrelado à "defesa do Ocidente", foi a arma ideológica que as direitas uruguaias se valeram para a manutenção no poder. O discurso do "caos comunista" externo encarnado na URSS e na China Maoísta aparecia não como um fenômeno distante, mas uma "ameaça real" a partir da construção ideológica sobre a Revolução Cubana.

Este conglomerado anticomunista alertaba a la ciudadania, pero además mantuvo una actitud exigente y fiscalizadora ante los gobernantes y los poderes públicos. (BROQUETAS, 2014, p. 102)

A pressão social dos diversos setores da direita uruguaia levou não apenas a um anticomunismo coeso como também ao surgimento de um clima de violência latente, ou seja, não apenas estavam preparados para o discurso, mas também para a prática repressiva contra a sociedade.

En 1960 varias manifestaciones desembocaran en hechos de violencia. El 16 de agosto, con finalidad de 'enjuiciar la conducta del actual Gobierno cubano', El MEDL organizo un acto en las inmediaciones del Ateneo de Montevideo, cuyo edificio fue aprovechado para colgar dos grandes banderas nacionales. La manifestación, a la que adhirieron varios movimientos anticomunistas, coincidió con un mitin, organizado por el Plenario Obrero Estudantil en la Explanada de la Universidad de la República, seguido de una manifestación que desembocó en las calles Agraciada y Colonia. Tras la finalización de acto de Plenario Obrero Estudantil, un grupo tomó por 18 de Julio coreando 'Cuba si, yankis no'. Al llegar AL Ateneo arrancaron los carteles de MEDL, y dieron inicio asi a una serie de episodios confusos y violentos. (BROQUETAS, 2014, p. 107)

O capítulo é finalizado com uma reflexão sobre as limitações do regime democrático diante da ação das direitas e sua ação sobre a população. Logicamente, diante das fragilidades criadas pelos próprios setores conservadores e liberais, a resposta era a repressão sobre a população. Como bem demonstra Magdalena Broquetas, 
diante da reação popular, ocorreu um recrudescimento pelo Estado da repressão.

No quarto capítulo centraliza suas atenções em um movimento de direita chamado de Legião Artiguista (Legión Artiguista). Este grupo estava no meio termo entre as duas "correntes" da direita uruguaia: manteve em si bases tanto da corrente "democrata" como a da "conservadora". Contudo, estava mais próxima dos conservadores.

A mediados de 1961 se presentó publicamente la Legión Artiguista, una organización que compartía varios de los postulados y modos de acción de la derecha conservadora, aunque ya desde su denominación, alusiva a la reunión de cuerpos militares, presentó diferencias significativas que la alejaban de sus contemporaneos 'democratas'. (BROQUETAS, 2014, p. 107)

Sua principal característica - ou estratégia de ação - foi um nacionalismo exacerbado. Aliás, dentro dessa "estratégia" estava um antiliberalismo, elemento que gerava simpatias no seio das forças armadas, tanto do ponto de vista político como econômico. Além disso, foi a Legião Artiguista que teria adotado pela primeira vez os pressupostos da Doutrina de Segurança Nacional e de onde teriam surgido as primeiras propostas golpistas na década de 1960 no Uruguai. A Legião era influenciada pelos estadunidenses e tinha como exemplo a ditadura brasileira de Castelo Branco. Ou seja, possuía por base um anticomunismo ferrenho na qual se colocava dentro da "zona de influência" do mundo ocidental contra o comunismo, seja na sua vertente externa (URSS, China e Cuba) como nos grupos internos.

O quinto capítulo aprofunda as discussões em torno da extrema direita nacionalista. Ao mesmo tempo, reflete, como no caso do terceiro capítulo, uma discussão contextual contraponto os impactos da Guerra Fria externa e internamente no Uruguai. Diante do alargamento da crise interna e dentro do sistema capitalista global, a extrema direita uruguaia assume um discurso antiliberal, além do anticomunista tradicional. Não apenas isso, mas determinadas vertentes vão adotar também o discurso antissemita. Dessa forma, em vários pressupostos tais grupos da extrema direita uruguaia terão pontos em comum com o antigo fascismo das décadas de 1920 e 1930 europeias. A autora demonstra que tais grupos não ficaram apenas no discurso de ódio, mas partiram para a violência e para o terrorismo. 
Los sentimientos de antisemitismo con un fuerte componente de antisionismo y anti-izquierdismo impulsaron y justificaron, con diversos grados de elaboración doctrinaria, las acciones violentas de los movimientos nacionalistas que, por norma general, respondieron a los derroteros de contexto internacional y arrojan nuevos indícios sobre los vinculos con los nacionalistas de derecha argentinos. [...] Por tal motivo el título de este apartado remite al carácter 'terrorista' de este tipo de violencia. (BROQUETAS, 2014, p. 185)

O penúltimo capítulo busca refletir sobre como agiram as direitas uruguaias no poder, utilizando o aparato do Estado em seu favor. Nessa parte, a autora examina alguns pontos em comum dos diversos grupos que compõem a direita com representatividade política. Da mesma forma, analisa os padrões de comportamento desses grupos nas diversas esferas dentro do governo em relação ao regime democrático. Por fim, analisa os pontos de convergências e divergências entre os grupos vinculados aos "democratas" e "nacionalistas". A estigmatização dos movimentos sociais e a repressão da esquerda, o fim das liberdades públicas ante o discurso de segurança nacional, a repressão política e o combate ao sindicalismo também são pontos abordados nesse capítulo.

O último capítulo é quase que um apanhado geral, voltado a mostrar as relações dos grupos de direita uruguaios (tanto em movimentos políticos como na estrutura do Estado) com Washington. Aborda a ação da CIA no período analisado assim como grupos internos (principalmente vinculados ao "ruralismo") que participaram da repressão política.

Pudieron reconocerse ligaciones congretas con el ruralismo (en las trayectorias militantes y las campañas compartidas) y fundamentalmente vínculos con los brazos represivos del Estado y altas autoridades policiales y militares. Asimismo, las conexiones entre movimentos civiles derechistas, autoritarios y partidarios de las acciones armadas con las fuerzas de seguridad se produjo a través de figuras sindicadas como elementos de enlace de la CIA en Uruguay, todo lo cual convergió en los inicios de la organización de grupos parapoliciales y paramilitares nutridos y amparados por un vasto conglomerado social que tenia internalizada la noción de 'guerra contrarrevolucionaria' y la Doctrina de la Seguridad Nacional. (BROQUETAS, 2014, p. 254)

Ao analisar a obra da historiadora uruguaia Magdalena Broquetas, percebemos que a autora se propôs a fazer uma pesquisa complexa, multifacetada e que foge do senso comum ao revelar não uma direita única 
- como tendemos a ver - mas uma verdadeira trama de diversos grupos e tendências distintas enquadradas como direitas - no plural. Um estudo amplo, porém, abordado com maestria na qual a própria amplitude não se perdeu em discussões superficiais. Ao contrário, consegue imprimir uma complexidade temática, acrescida de uma excelente qualidade narrativa que permite ao leitor uma plena compreensão de um texto cuja leitura transcorre como se fosse um romance.

Ao terminar a leitura da obra, fica aquele sentimento de vazio, de algo não contado, de que a autora avançasse para as décadas seguintes e abordasse o período ditatorial iniciado por Juan María Bordaberry, em 1973, e que se entendeu até 1985. Porém, seria outro trabalho. O objetivo de Magdalena Broquetas foi mostrar como se estruturou a "trama autoritária" que levaria a esse período de terror, fugindo da concepção tradicional das direitas latino-americanas de colocar suas ações como uma reação nacionalista diante do "caos esquerdista", objetivando justificar suas ações escusas. Ao contrário, Broquetas, foi na contracorrente do tradicional, mostrando como se gestaram, estruturaram e agiram estas direitas no período que antecedeu a ditadura.

\section{Rodrigo Santos de Oliveira}

Doutor em História das Sociedades Ibéricas e Americanas pela Pontifícia Universidade Católica do Rio Grande do Sul (PUCRS).

Professor Adjunto dos cursos de Bacharelado e Licenciatura em História da Universidade Federal do Rio Grande (UFRG). <oliv.rod@hotmail.com> 